\title{
TERMINATION OF THE COMMON FACIAL VEIN INTO THE ANTERIOR JUGULAR VEIN: A RARE CASE REPORT
}

\author{
Sushil Kumar*, Ritwik Baidya. \\ Anatomy division, Department of radiology, Weill Cornell Medicine, New York.

\section{ABSTRACT}

The facial vein drains the facial region of our body. It unites with the anterior division of the retromandibular vein to form the common facial vein. In this case report, the retromandibular vein was seen dividing normally into the anterior and posterior divisions. The posterior division was seen uniting with the posterior auricular vein to form the external jugular vein. Formation and course of the external jugular vein was normal. The anterior division of the retromandibular vein was uniting with the facial vein to form the common facial vein, which was draining into the anterior jugular vein instead of the internal jugular vein.

KEY WORDS: Face, Jugular, Retromandibular, Sternocleidomastoid, Vein.

Address for Correspondence: Dr. Sushil Kumar, Assistant professor, Anatomy division, Department of radiology, Weill Cornell Medicine, New York. E-Mail: sushilbhu2001@yahoo.co.in

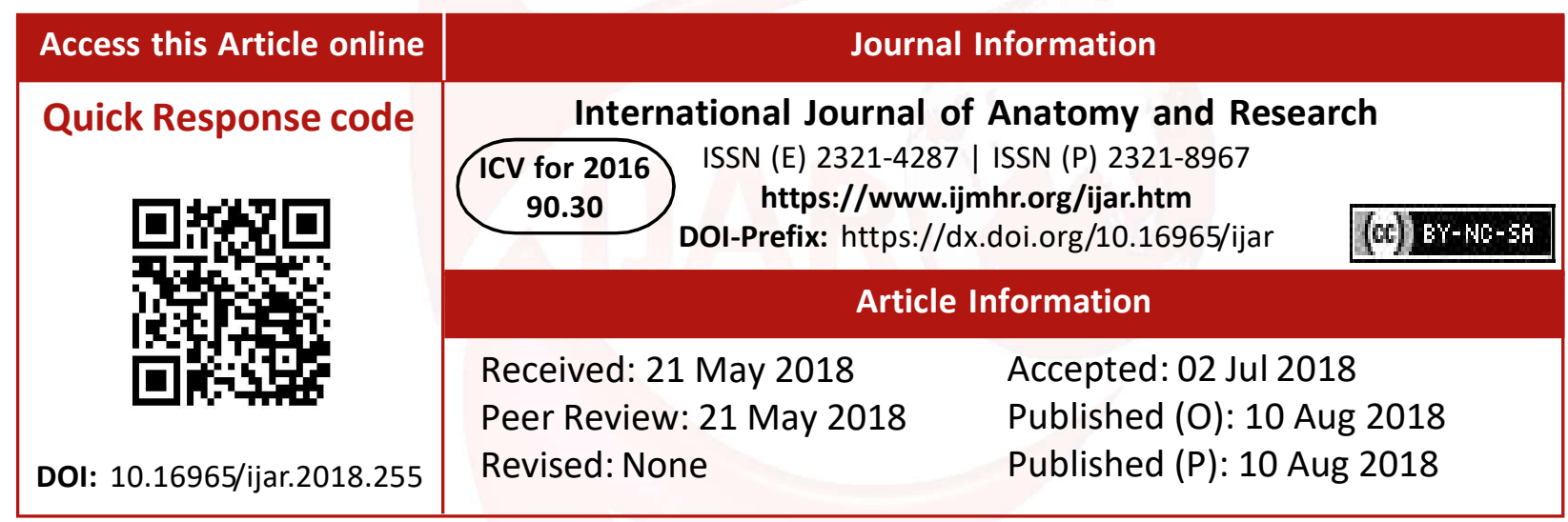

\section{INTRODUCTION}

Facial vein, a continuation of the angular vein, is the main vein draining the face. Anteroinferior to the mandibular angle, it is joined by anterior division of the retromandibular vein to form the common facial vein which drains into the internal jugular vein. The posterior division of the retromandibular vein unites with the posterior auricular vein and forms the external jugular vein.

Anterior jugular vein arises near the hyoid bone from the confluence of superficial submandibular veins. It descends approximately midway in between midline and the anterior border of the sternocleidomastoid. Turning laterally, low in the neck, deep to sternocleidomastoid, it either joins the terminal part of the of the external jugular vein or may enter the subclavian vein directly [1].

We present a rare anatomical variation in which the anterior division of the retromandibular vein was draining into the anterior jugular vein. The facial vein was uniting with the submental vein and was draining into the anterior jugular vein.

\section{CASE REPORT}

During dissection of a 58-year-old male cadaver, we observed one unique variation in the course of the retromandibular vein on the right side of the face. The retromandibular vein was formed normally by the union of the maxillary vein and the superficial temporal vein. After having a short course within the parotid gland it splits into an anterior and posterior division (fig.1). The retromandibular vein was $2.63 \mathrm{~cm}$ in length, whereas the anterior and posterior divisions were $2.4 \mathrm{~cm}$ and $1.83 \mathrm{~cm}$ in length respectively. The course of the posterior division was normal; it united with the posterior auricular vein to form external jugular vein. The anterior division was uniting with the facial vein and draining into the 
anterior jugular vein. The course of anterior jugular vein was normal.

Fig. 1: Showing the course of facial vein.

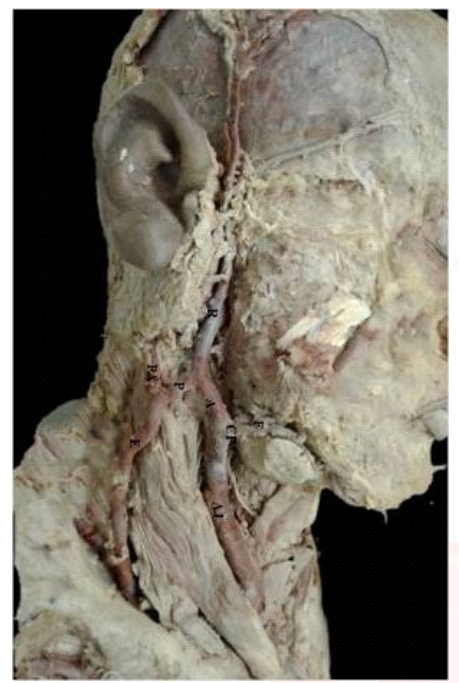

$\mathrm{R}$ - retromandibular vein, $\mathrm{A}$ - anterior division,

$\mathrm{P}$ - posterior division, PA - posterior auricular vein,

$\mathrm{E}$ - external jugular vein, $\mathrm{CF}$ - common facial vein,

$\mathrm{F}$ - facial vein, AJ - anterior jugular vein

\section{RESULTS AND DISCUSSION}

Variation in the vascular system of our body is a common feature and more prevalent in veins that arteries [2]. There have been many reported variations in drainage pattern of the facial vein. One of the common variation is the drainage of the facial vein in external jugular vein; incidence of which vary from $5 \%$ - $9 \%[3,4]$. Many different variations in the termination of the facial vein have been reported. Bertha $A$ and Suganthy Rabi reported a case in which facial vein was terminating into the subclavian vein [5]. Shilpa Bathla et al. reported a case in which facial vein bifurcated into two divisions at the base of mandible posterior to the facial artery, one division terminated into the anterior jugular vein while other one into the external jugular vein [6]. Peuker et al reported a case in which the facial vein was draing into the superficial temporal vein [7]. Choudhary et al reported a case in which the retromandibular vein was continuing as the external jugular vein without dividing into an anterior and posterior division. The facial vein and posterior auricular vein were draining into the external jugular vein [8].

Abhinitha et al reported an interesting case in which external jugular vein was absent and the retromandibular vein was wide in caliber. Its anterior division joined the facial vein to for the common facial vein, which drained into the anterior jugular vein instead of the internal jugular vein. The posterior division drained directly into the internal jugular vein [9].

Nayak reported a case in which the anterior division of the retromandibular vein was absent while the anterior jugular vein was a continuation of the facial vein. There was a large communicating vein between the anterior jugular vein and the anterior division of internal jugular vein. The lingual vein was draining into the communicating vein [10]. Our case is unique in the sense that the anterior division of retromandibular vein was continuing as anterior jugular vein and the facial vein was draining into anterior jugular vein after receiving submental vein.

\section{CONCLUSION}

Variation of the facial veins and arteries are of great clinical significance. The knowledge of their presence is important for the surgeon doing facial flaps and transplantation because they are the main vascular pedicles that will be connected to the patient. A good arterial inflow and venous drainage are essential for the free flap survival. Several authors recommend preoperative investigation in a brain dead donor before performing any facial transplantation $[11,12,13]$. Superficial veins of head and neck are also used for carotid endarterectomy and for oral reconstructive surgeries, where facial vein is often needed for microvascular anastomosis [14].

\section{Conflicts of Interests: None}

\section{REFERENCES}

[1]. Standring S. Gray's anatomy. The anatomical basis of clinical practice. $41^{\text {st }}$ ed. London: Elsevier; 2016. p. 459-505.

[2]. Hollinshead WH. Anatomy for Surgeons. $3^{\text {rd }}$ ed. New York: Harper \& Row;1982. p. 467-69.

[3]. Choudhry R, Tuli A, Choudhry S. Facial vein terminating in the external jugular vein-an embryologic interpretation. Surg Radiol Anat 1997; 19: 73-77.

[4]. Gupta V, Tuli A, Choudhry R, Agarwal S, Mangal A. Facial vein draining into external jugular vein in humans: its variations, phylogenetic retention and clinical relevance. Surg Radiol Anat 2003; 25(1): 36-41.

[5]. Bertha A and Suganthy Rabi. Journal of Clinical and Diagnostic Research. 2011; 5(1): 24-27. 
[6]. Shilpa bathla, Ritu Singroha, S.K. Srivastava. Variation in termination of facial vein-a rare case report. Eur J Anat 2012; 16(3): 212-15.

[7]. Peuker ET, Fischer G, Filler TJ. Facial vein terminating in the superficial temporal vein: a case report. J Anat 2001;198 (4): 509-10.

[8]. Choudhary Shahnaz, Sharma Ashwani K, Singh Harbans. Undivided retromandibular vein continuing as external jugular vein with facial vein draining into it: An anatomical variation. JK science 2010; 12 (4): 203-04.

[9]. Abhinitha P, Rao MKG, Kumar N, Nayak SB, Ravindra SS, Aithal PA. Absence of the external jugular vein and an abnormal drainage pattern in the veins of the neck OA Anatomy 2013; 01(2):15.

[10]. Nayak BS. Surgically important variations of the jugular veins. Clin Anat 2006. 19(6): 544-546.
[11]. Renshaw A, Whitwell KA, Berger L. The use of color Doppler ultrasound in the assessment of vessels for facial transplantation. Ann Plast Surg 2007;59: 82-86.

[12]. Lohn JW, Penn JW, Norton J. The course and variation of the facial artery and vein: implications for facial transplantation and facial surgery. Ann Plast Surg 2011; 67:184-188.

[13]. Bondaz M, Ricard AS, Berge J. Hypoplastic facial artery and allotransplantation of the lower twothirds of the face: an anatomical study. Plast Reconstr Surg 2012; 129: 369-371.

[14]. Sabharwal P, Mukerjee D. Autogenous common facial vein or external jugular vein patch for carotid endarterectomy. Cardiovascular Surgery 1998; 6: 594-597.

How to cite this article:

Sushil Kumar, Ritwik Baidya. TERMINATION OF THE COMMON FACIAL VEIN INTO THE ANTERIOR JUGULAR VEIN: A RARE CASE REPORT. Int J Anat Res 2018;6(3.2):5501-5503. DOI: 10.16965/ ijar.2018.255 